disadvantages of new media, including the quality of content and style of presentation. The article points out the great educational role of traditional media in comparison with new ones and a higher professional level of journalists compared to bloggers. The authors determine possibilities for the preservation and effective functioning of traditional media in the nearest future. The paper compares the situation with new media to the situation with tokenized payments in the modern Russia. The authors believe there is an opportunity to increase the audience of new media.

Keywords: traditional media, new media, relationships, perspectives, blogging, political sphere

АБРАМОВ Валерий Леонидович - доктор экономических наук, профессор; главный научный сотрудник Центра социально-политических исследований Института развития интеграционных процессов Всероссийской академии внешней торговли (117312, Россия, Москва, ул. Вавилова, 7); главный научный сотрудник Института исследований международных экономических отношений Финансового университета при Правительстве РФ (125993, Россия, г. Москва, ГСП-3, Ленинградский $n p-\kappa m, 49 ;$ valabr@yandex.ru)

ЖИВАЛОВ Владимир Николаевич - доктор экономических наук, член РАЕН; аналитик Центра социально-политических исследований Института развития интеграционных процессов Всероссийской академии внешней торговли (117312, Россия, г. Москва, ул. Вавилова, 7; vzhivalov@ vavt.ru); профессор Российской академии народного хозяйства и государственной службы при Президенте РФ (119571, Россия, г. Москва, пр-кт Вернадского, 82, стр. 1)

ИВАНЧЕНКО Виктория Сергеевна - аналитик Центра социально-политических исследований Института развития интеграционных процессов Всероссийской академии внешней торговли Министерства экономического развития РФ (117312, Россия, г. Москва, ул. Вавилова, 7; viktoriia. ivanchenko@gmail.com)

ПЕРЕХОД Елена Константиновна - аналитик Центра социально-политических исследований Института развития интеграционных процессов Всероссийской академии внешней торговли Министерства экономического развития (117312, Россия, г. Москва, ул. Вавилова, 7; ереrekhod@ vavt.ru)

ЧИМИРИС Екатерина Сергеевна - кандидат политических наук, аналитик 1-й категории Центра социально-политических исследований Института развития интеграционных процессов Всероссийской академии внешней торговли Министерства экономического развития (117312, Россия, г. Москва, ул. Вавилова, 7); доцент департамента политологии факультета социальных наук и массовых коммуникаций Финансового университета при Правительстве РФ (125993, Россия, 2. Москва, ГСП-3, Ленинградский пр-кm, 49; Chimiris@gmail.com)

чИСТИЛИН Дмитрий Константинович - кандидат экономических наук, академик РАЕН; руководитель Центра социально-политических исследований Института развития интеграционных процессов Всероссийской академии внешней торговли (117312, Россия, г. Москва, ул. Вавилова, 7; chistilin@vavt.ru)

\title{
ЭКСПЕРТНЫЕ ПОДХОДЫ К ИССЛЕДОВАНИЮ СОЦИАЛЬНЫХ СЕТЕЙ В ИНТЕРНЕТЕ НА ПОСТСОВЕТСКОМ ПРОСТРАНСТВЕ (на примере Молдовы)
}

\footnotetext{
Аннотация. Влияние социальных сетей в современном мире сложно переоценить. Они стали полноценным каналом политической коммуникации и формирования общественного мнения. В случае применения специальных методов анализа материалы социальных сетей открывают большие возможности для прогнозирования и формирования коллективного поведения населения. Гипотеза авторов заключается
} 
в том, что граждане прозападно ориентированных стран постсоветского пространства чаще выбирают Facebook в качестве основной площадки для общения в сети Интернет, тогда как русскоязычные сети ВКонтакте и Одноклассники являются для них менее привлекательными и рассматриваются в качестве опасных платформ продвижения «российской пропаганды». В данной статье авторы ставят перед собой задачу сделать обзор исследований и подходов к анализу социальных сетей на постсоветском пространстве. Авторы дают выборочный обзор статистики по использованию разных (избранных) социальных сетей в странах ближайшего зарубежья. На материале конкретного исследования показано, как происходит частичное искажение данных и выводов относительно использования социальных сетей на постсоветском пространстве.

Ключевые слова: социальные сети, общественное мнение, пропаганда, постсоветское пространство, Россия

A ктивное развитие коммуникации в Интернете стало возможным в первую очередь благодаря появлению социальных сетей. Новые технологии открыли для политического $P R$ и политтехнологов невиданные ранее возможности по воздействию на общественное мнение. Однако вместе с ростом охвата населения сетью Интернет наблюдается рост апатии и снижение количества реальных политических действий. Пользователи социальных сетей становятся все более придирчивыми к контенту, и среди политических технологов развернулась борьба за внимание аудитории. Противостояние в информационной среде существует и на международном уровне. В последнее время все чаще говорят о Twitter-дипломатии [Dombrowski, Reich 2018] и политических мемах [Coker 2008] как инструментах воздействия на общественные и международные процессы.

Россия и Запад ведут борьбу за доминирование в повестке дня в странах постсоветского пространства, в т.ч. и посредством использования социальных сетей. Малые страны постсоветского пространства обеспокоены усилением геополитической значимости России и ищут варианты выстраивания взаимовыгодного сотрудничества с ней [Абрамов 2019]. Также социальные сети стали своеобразным символом и инструментом активизации коллективных действий. Эксперты спорят относительно степени влияния социальных медиа в событиях Арабской весны [Susser 2012]. Вне зависимости от того, являются ли социальные сети катализатором протестных действий, они играют все более значимую роль в организации и координации социальной активности.

Социальные сети - важный источник политического дискурса, т.к. в интернет-среде люди высказываются более свободно (часто это связано с мнимым ощущением анонимности), а значит, исследователи могут приблизиться к пониманию реальных настроений [Чимирис 2007]. Сеть становится альтернативным источником данных об общественном мнении, и социологические опросы уходят на второй план. При наличии инструментов существует возможность анализировать данные, не спрашивая людей специально, - они выдают эту информацию самостоятельно.

Все описанные аспекты работают, когда люди имеют возможность и желание пользоваться социальными сетями. В связи с этим важно посмотреть на охват основными социальными сетями населения того или иного государства. Базовая гипотеза данной статьи заключается в том, что существует прямая взаимосвязь между ростом использования сети Facebook и внешнеполитической ориентацией страны на западные стандарты и институты.

В этой статье мы рассмотрим статистику использования социальных сетей населением трех стран постсоветского пространства - Грузии, Молдовы и Украины, которые вступили в проект ЕС «Восточное партнерство» и заключили договор об ассоциации. В результате они оказались оторванными от поли- 
тического, экономического и социального влияния России. Также рассмотрим степень влияния социальных сетей на политическую ориентацию населения в этих странах, повлекшего одобрение прозападной ориентации политики, и покажем риски, с которыми могут столкнуться исследователи при анализе социальных сетей. В качестве базового кейса рассмотрим исследование, проведенное в Молдове и посвященное анализу «российской пропаганды» в социальной сети «Одноклассники», на предмет его политизированности.

\section{Терминология и методы изучения социальных сетей}

Сетевая логика взаимодействия между людьми появилась задолго до всплеска новых технологий в информационную эпоху. Интернет просто отобразил то, что уже существовало в реальности - сетевые взаимодействия в обществе, и дал дополнительный инструмент для коммуникации [Сергеев и др. 2007]. В связи с этим часто происходит смешение понятий, т.к. социальными сетями называют как подход в политической социологии к исследованию структур взаимодействий социальных и политических акторов, так и специальные интернет-ресурсы для общения и обмена информацией. Второй феномен потенциально может дать большие данные для исследований в рамках $S N A$ (в т.ч. с применением теории графов) [Wellman 1983; Hafner-Burton, Kahler, Montgomery 2009]. В данной статье мы сделаем акцент на исследовании влияния социальных сетей во втором их понимании (как специальные интернетресурсы).

С другой стороны, обилие текстового и графического контента в социальных сетях дает возможность применять разнообразные методы анализа дискурса. Анализ дискурса социальных сетей и мемов применяется для оценки и прогнозирования протестной активности, инструментов пропаганды и информационного воздействия, использования мягкой силы (результатов и возможностей). Исследование протестной активности в социальных сетях ведется в основном постфактум, хотя наиболее интересная исследовательская задача состоит в том, чтобы прогнозировать рост такой активности, пока она не вылилась в реальное пространство политики [Азаров и др. 2014].

Социальные сети - это особый вид источника данных, но к нему в целом применимы методы, которые используются для анализа текста: контент-анализ [Черемисова 2016], интент-анализ [Радина 2016], когнитивное картирование [Sharma, Kandwal, Khatri 2018], критический дискурс-анализ [Triana et al. 2020], семиотическое моделирование [Свиркин и др. 2016]. Плюсы методики в том, что мы имеем возможность анализировать большие массивы открытых данных, однако может возникнуть иллюзия, что единственно возможными будут количественные методы анализа. Тем не менее современные методики позволяют комбинировать качественные и количественные методы анализа текста. Положительное отличие источника данных из социальных сетей также состоит в том, что здесь могут быть применены методы исследования больших данных, можно анализировать цифровой след, который оставляют пользователи.

\section{Распространение социальных сетей на постсоветском пространстве}

Жители стран постсоветского пространства имеют неравный доступ к пользованию сетью Интернет, что во многом определяет их присутствие в социальных сетях, количество времени, проведенное в них, и цели пребывания. Политический контент наиболее часто получает распространение в таких социальных сетях, как ВКонтакте, Facebook и Twitter [Козырева 2015]. Также нужно отметить, что сети Одноклассники и ВКонтакте запрещены в Украине 
на законодательном уровне с 2017 г. В мае 2020 г. президент Зеленский продлил этот запрет еще на три года ${ }^{1}$. В формировании социально-политической повестки этих стран доминирует Facebook.

В рамках данного анализа мы рассмотрим три социальные сети: Facebook выбран в связи с тем, что он активно использовался в период Евромайдана на Украине, ВКонтакте и Одноклассники важны для анализа как канал коммуникации на русском языке в сети Интернет.

Facebook. Facebook является наиболее популярной социальной сетью в мире. Ее ежемесячная аудитория составляет более 2 млрд чел. ${ }^{2}$ Обладая информацией о таком числе граждан, Facebook закономерно используется для продвижения политических целей. С 2006 г. сеть доступна всем пользователям старше 13 лет, имеющим электронную почту. Компания Facebook Inc. также является владельцем других популярных сервисов, таких как Instagram, WhatsApp.

Таблица 1

Охват населения стран постсоветского пространства социальной сетью Facebook с разбивкой по возрастным категориям

\begin{tabular}{|l|c|c|c|c|c|c|c|c|}
\hline \multicolumn{1}{|c|}{ Страна } & $\begin{array}{c}\text { Всего, } \\
\text { тыс. чел. }\end{array}$ & $\mathbf{1 8 - 2 4}$ & $\mathbf{2 5 - 3 4}$ & $\mathbf{3 5 - 4 4}$ & $\mathbf{4 5 - 5 4}$ & $\mathbf{5 5 - 6 4}$ & $\mathbf{6 5 +}$ & $\begin{array}{c}\text { Доля } \\
\text { населения } \\
\text { в Facebook, \% }\end{array}$ \\
\hline Грузия & 2250 & 471 & 684 & 473 & 316 & 204 & 113 & 59,6 \\
\hline Армения & 1250 & 237 & 406 & 269 & 157 & 132 & 56 & 40,7 \\
\hline Молдова & 1250 & 218 & 392 & 286 & 182 & 128 & 45 & 30,8 \\
\hline Украина & 12500 & 1500 & 3700 & 3225 & 2150 & 1350 & 500 & 28,6 \\
\hline Азербайджан & 1750 & 298 & 662 & 410 & 203 & 138 & 46 & 16,8 \\
\hline Кыргызстан & 650 & 96 & 244 & 171 & 88 & 42 & 16 & 10,0 \\
\hline Казахстан & 1750 & 121 & 565 & 568 & 300 & 151 & 44 & 9,2 \\
\hline Беларусь & 650 & 43 & 189 & 222 & 114 & 60 & 23 & 6,8 \\
\hline Узбекистан & 1250 & 188 & 505 & 346 & 133 & 58 & 21 & 3,7 \\
\hline Таджикистан & 275 & 26 & 46 & 27 & 12 & 5 & 2 & 2,9 \\
\hline Туркменистан & 13 & 1 & 5 & 4 & 2 & 1 & 0 & 0,2 \\
\hline
\end{tabular}

Источник: По данным статистики аудитории Facebook. URL: https://www.facebook.com/ ads/audience-insights/people?act=122491739154607\&age=18- (проверено 10.02.2020).

По данным Facebook, аудитория сети в странах постсоветского пространства составляет около 24 млн чел., более половины из них - жители Грузии, Молдовы и Украины ${ }^{3}$. Из них 54\% женщин и 46\% мужчин. Наиболее популярна сеть среди людей в возрасте от 25 до 54 лет (см. табл. 1) и имеющих высшее образование (см. рис. 1).

1 Еще на три года: Зеленский продлил запрет российских соцсетей. - Газета.ру. 15.05.2020. Доступ: https://www.gazeta.ru/tech/2020/05/15/13083811/zelensky.shtml (проверено 09.11.2020).

2 Most popular social networks worldwide as of January 2020, ranked by number of active users. - Statista. URL: https://www.statista.com/statistics/272014/global-social-networks-ranked-bynumber-of-users/ (accessed 04.02.2020).

3 По данным статистики аудитории Facebook. Доступ: https://www.facebook.com/ads/ audience-insights/people?act=122491739154607\&age=18- $($ проверено 10.02.2020) 


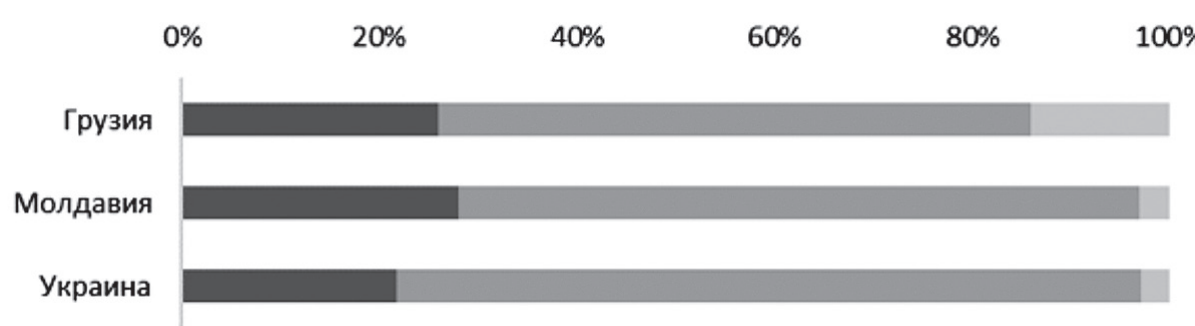

- Среднее Высшее Аспирантура/Магистратура

Источник: по данным статистики аудитории Facebook. URL: https://www.facebook.com/ ads/audience-insights/people?act $=122491739154607 \& a g e=18-($ проверено 10.02.2020)

Рисунок 1. Уровень образования пользователей Facebook в Грузии, Молдове и Украине

ВКонтакте. Основана в 2006 г. П. Дуровым при финансовой поддержке семьи Мирилашвили. Сайт ВКонтакте занимает 13-е место по популярности в мире, 4-е место среди социальных сетей ${ }^{1}$.

Таблииа 2

\section{Охват населения Грузии, Молдовы и Украины социальной сетью ВКонтакте}

\begin{tabular}{|l|c|c|}
\hline \multicolumn{1}{|c|}{ Страна } & Всего, тыс. чел. & Доля населения в сети ВКонтакте, \% \\
\hline Украина & 7236 & 29,32 \\
\hline Грузия & 490 & 13 \\
\hline Молдавия & 203 & 5 \\
\hline
\end{tabular}

Источник: Digital Report. Доступ: https://digital.report/internet-gruziya/; Sputnik Moldova. Доступ: https://ru.sputnik.md/society/20180926/22106385/samaia-populiarnaia-socsetimoldova.html; Kantar. Доступ: https://tns-ua.com/news/reyting-populyarnih-saytiv-zatraven-2018 (проверено 10.11.2020).

Одноклассники. Создана А. Попковым в 2006 г. Владелец сети - А. Усманов, который также является собственником компании Mail.Group.

Таблица 3

Охват населения Грузии, Молдовы и Украины социальной сетью Одноклассники

\begin{tabular}{|l|c|c|}
\hline \multicolumn{1}{|c|}{ Страна } & Всего, тыс. чел. & Доля населения в сети Одноклассники, \% \\
\hline Грузия & 1508 & 40 \\
\hline Украина & 4028 & 16 \\
\hline Молдова & 365 & 9 \\
\hline
\end{tabular}

Источник: Digital Report. Доступ: https://digital.report/internet-gruziya/; Sputnik Moldova. Доступ: https://ru.sputnik.md/society/20180926/22106385/samaia-populiarnaia-socsetimoldova.html; Kantar. Доступ: https://tns-ua.com/news/reyting-populyarnih-saytiv-zatraven-2018 (проверено 10.11.2020).

1 Top Websites Ranking. - SimilarWeb.com. URL: https://www.similarweb.com/top-websites/category/computers-electronics-and-technology/social-networks-and-online-communities (accessed 10.11.2020). 
Данные статистики показывают, что в Молдове в основном используют социальную сеть Facebook (30,8\% населения), распространение сети Одноклассники наиболее низкое по сравнению с Беларуью и Украиной (9\% населения). Тем не менее в силу допущения, что страна, в которой расположена социальная сеть, оказывает влияние на содержание и повестку размещаемой информации, экспертное сообщество Молдовы сконцентрировало внимание на сети Одноклассники с целью выявить там факты применения российской пропаганды. Рассмотрим логику этого исследования.

Статистика показывает, что во всех анализируемых странах наибольший охват населения, формирующий социально-политическую политику, имеет сеть Facebook. Сети Одноклассники и ВКонтакте уступают ей по охвату населения, а значит и по степени влияния. В Украине эти сети запрещены к использованию населением, которому провайдеры Интернета ограничили доступ, и Facebook имеет неограниченные возможности по охвату населения и формированию политической и социальной повестки. В Молдове наблюдается максимальная разница между российскими сетями и сетью Facebook в охвате населения в пользу последнего. Поэтому рассматриваемый нами аналитический кейс имеет особое, принципиальное значение.

\section{Социальные сети как фактор политики в Молдове}

Численность населения Молдовы составляет 4,05 млн чел. Интернетпользователями являются $76 \%$ населения страны ${ }^{1}$. Социальные сети находятся в процессе перераспределения аудитории: все больше жителей отказываются от сети Одноклассники в пользу Facebook. С 2017 г. ежегодный прирост пользователей Facebook в Молдове составляет около 20\%. На начало 2020 г. Facebook используют около 1,25 млн чел. Сеть популярна среди людей в возрасте до 44 лет (см. табл. 1), значительна доля молодой аудитории (до 24 лет) - $17 \%$ всех пользователей. $36 \%$ пользователей из Молдовы работают в сфере менеджмента, $21 \%$ - в сфере искусства и развлечений, $20 \%$ оказывают административные услуги, $18 \%$ работают в сфере образования. $50 \%$ пользователей используют отображение своей страницы на Facebook на русском языке, 45\% - на румынском, $3 \%$ - на английском.

Социальные сети в Молдове расцениваются местными политтехнологами как один из наиболее эффективных способов влияния на выбор молдавского избирателя и активно используются для ведения предвыборных кампаний. Мониторинг фонда Youth Development for Innovation показывает ${ }^{2}$, что платформами социальных сетей, наиболее часто используемыми конкурентами на выборах, являются Facebook и Одноклассники: свою страницу или группу в этих сетях имеют свыше 80\% конкурентов. Две другие платформы, YouTube и Instagram, периодически используют примерно 60-80\% электоральных конкурентов в ходе кампании по парламентским выборам. Согласно отчету, наибольшую активность на четырех платформах проявляют Партия действия и солидарности (Facebook), Партия социалистов (Одноклассники), Демократическая партия (Instagram). В то же время на YouTube Демократическая партия и Партия действия и солидарности демонстрируют одинаковый уровень активности.

Формируется парадокс, при котором Россия, с одной стороны, не сильно про-

1 Individuals using the Internet (\% of population). - The World Bank. URL: https://data.worldbank.org/indicator/it.net.user.zs (accessed 10.11.2020).

2 В каких социальных сетях работают партии. - Молдавские ведомости. 31.01.2019. Доступ: http://www.vedomosti.md/news/v-kakih-socialnyh-setyah-rabotayut-partii (проверено 10.11.2020) 
двинулась в использовании информационных инструментов «мягкой силы», с другой - некоторые страны постсоветского пространства обвиняют Россию в активной пропаганде в социальных сетях. Молдова представляет собой интересный кейс и экспертный дискурс по этому вопросу. Рассмотрим доклад, который выпустил Институт общественных политик Молдовы [Российская пропаганда... 2018].

Авторы доклада считают, что Россия оказывает значительное влияние на общественное мнение Молдовы через социальную сеть Одноклассники. В качестве основного метода анализа использовался контент-анализ, который показывает частотность употребления слов. С точки зрения авторов доклада, информационные «посылы содержат мало конструктивных элементов в том, что касается публичной политики, порядка организации гражданских акций и форм, в которых граждане Республики Молдова могут способствовать развитию своей собственной страны. Следовательно, правильно будет охарактеризовать данные посылы как пропаганду, направленную на достижение геополитических целей» [Российская пропаганда... 2018: 11].

Молдова называется пробной платформой для политики России в отношении стран ближнего зарубежья. Также Молдова может использоваться для влияния на Румынию. Эксперты Молдовы считают, что Россия стремится апробировать методику федерализации на примере Молдовы и затем использовать этот же метод в Украине. Исследователи видят два содержательных направления влияния России на Молдову, которые вписываются в рамки «молдовенизма»:

- Молдова как вассал великой державы, сентиментальные связи с советским прошлым;

- подрыв национальных истоков идентичности, антирумынские настроения: «российская пропаганда усиливает комплексы неполноценности, связанные с провалами проекта молдавской государственности, подпитывает сепаратистские настроения в различных регионах, наращивает этноязыковой раскол в обществе».

Темы, которые, по мнению молдавских экспертов, Россия эксплуатирует в своей пропаганде:

- признание румынского языка в качестве второго государственного ведет к объединению Молдовы и Румынии;

- возвышение роли СССР в период Великой Отечественной войны и формирование комплекса неполноценности в малых народах бывшего СССР, не русских по национальности;

- эксплуатация георгиевской ленты: «лента превратилась в символ связи между Владимиром Путиным и представителями сепаратистских режимов в Крыму, Приднестровском регионе, Донецке и Луганске - вплоть до протофашистских организаций и идеологий»;

- символическая монополизация Дня Победы;

- презрительное и уничижительное отображение современной Украины и прозападных украинских политиков;

- работа с соотечественниками на территории бывших советских республик, при том что сам термин до конца не определен;

- антиамериканские настроения;

- характеристика НАТО как агрессивного актора международных отношений;

- борьба в общественном поле между проектом ЕАЭС и ЕС;

- поддержка АТО Гагаузия и приоритет русского языка: жители АТО Гагаузия 
поддерживают Россию, пользуются русским языком и смотрят ТВ на русском языке.

Пропаганда подразумевает навязывание информационной повестки при недоступности альтернативных источников информации. В связи с этим вышеизложенные информационные тренды якобы российской пропаганды сложно отнести к данной категории по нескольким причинам. Во-первых, по всем этим вопросам в сети Интернет существует альтернативная точка зрения, в частности в той же социальной сети Одноклассники. Во-вторых, указанные тезисы отражают официальную позицию Российской Федерации и вписываются в ее политику «мягкой силы». Наконец, выбор ряда жителей Молдовы - говорить на русском языке нельзя считать результатом только российского влияния; это результат совместной истории и развития всего пространства России и ее ближайших соседей.

Вышеизложенные тезисы доклада отражают основной смысловой тренд «русофобской информационной войны», в силу чего элементом таковой можно считать и публикацию этого исследования. Судя по основным выводам рассматриваемого доклада, сама стратегия и политика России на постсоветском пространстве рассматривается проевропейски ориентированными экспертами как однозначная пропаганда. При этом обратим внимание, что основной признак пропаганды - отсутствие конструктивных посылов в отношении практики публичной политики и дипломатии, порядка организации гражданских акций и совершенствования институционального устройства страны. Россия действительно в рамках своей политики «мягкой силы» делает акцент на ценностях, а не практиках и институтах. Именно это воспринимается как пропаганда, а не информирование.

Рассмотренный пример показывает, как аналитика может стать одним из способов распространения антироссийской идеологии, а не объективным и взвешенным анализом контента.

Анализ социальных сетей в интернет-пространстве дает широкие возможности для исследователей и политических менеджеров. Большие данные открывают возможности для анализа как с применением количественных, так и качественных методов. При этом важно учитывать реальный охват населения той или иной страны социальными сетями. В частности, если в странах Восточной Европы этот процент высок, то для ряда стран Центральной Азии показатели иногда не превышают уровень статистической погрешности. Это означает, что методика работы со странами постсоветского пространства должна отличаться, и не существует возможности выработать единую модель взаимодействия в социальных сетях.

Рассмотренные нами статистические данные показывают, что Facebook постепенно расширяет свое информационное пространство в Интернете, в частности, Молдова постепенно переориентируется на использование этой социальной сети. Можно утверждать, что наблюдается прямая связь между максимизацией присутствия сети Facebook в Интернете стран постсоветского пространства, имеющих договор об ассоциации с ЕС, и происшедшими там общественными событиями в формате «цветной революции», что говорит о принципиальном прозападном формировании социально-политической повестки в этих странах на основе функционирования этой сети.

На этом фоне русскоязычные социальные сети Одноклассники и ВКонтакте постепенно сдают позиции. Однако проевропейские эксперты стран ближайшего зарубежья продолжают рассматривать Россию в качестве угрозы. В частности, «российская пропаганда» становится таким феноменом, который они стремятся найти в любом высказывании в социальных сетях. Эксперты 
не застрахованы от использования результатов исследований в политических целях. На примере исследования, проведенного в Молдове, мы показали, что непонимание специфики применения «мягкой силы» Россией на постсоветском пространстве может привести к неоправданным и политизированным выводам. Очевидно, что ряд пунктов информационной повестки России преднамеренно оцениваются как пропаганда и навязывание, хотя объективно они таковыми не являются.

\section{Список литературы}

Абрамов В.Л. 2019. Внешние политики государств - членов ЕАЭС с «малой экономикой» в условиях геополитической напряженности. - Этносоциум и межнациональная культура. № 10(136). С. 9-18.

Азаров А.А., Бродовская Е.В., Дмитриева О.В., Домбровская А.Ю., Фильченков А.А. 2014. Стратегии формирования установок протестного поведения в сети Интернет: опыт применения киберметрического анализа (на примере Евромайдана, ноябрь 2013 г.). Ч. І. - Мониторинг общественного мнения: экономические и социальные перемены. № 2. С. 63-78.

Козырева А.А. 2015. Почему социальные сети являются инструментом политической власти? - Вестник Кемеровского государственного университета. № 2-2(62). С. 56-59.

Радина Н.К. 2016. Интент-анализ онлайн-дискуссий (на примере комментирования материалов интернет-портала ИноСМИ.ru). - Медиаскоп. Вып. 4. Доступ: http://www.mediascope.ru/2238 (проверено 09.11.2020).

Российская пропаганда на сайте Одноклассники. Случай Республики Молдова. 2018. 68 с. Кишинев: Институт общественных политик. Доступ: http://ipp.md/ wp-content/uploads/2018/02/Odnoklassniki_ru.pdf (проверено 11.11.2020).

Свиркин М.В., Карелин В.В., Буре В.М., Екимов А.В. 2016. Имитационное моделирование социальной сети с двумя лидерами. - Вестник СПбГУ. Сер. 10. Прикладная математика. Вып. 1. С. 93-98.

Сергеев В.М., Кузьмин А.С., Нечаев В.Д., Алексеенкова Е.С. 2007. Доверие и пространственное взаимодействие социальных сетей. - Полис. Политические исследования. № 2. С. 8-17.

Черемисова И.В. 2016. Контент-анализ страниц активных пользователей социальной сети «ВКонтакте». - Вестник Волгоградского государственного университета. Сер. 11. Естественные науки. № 2(16). С. 74-79.

Чимирис Е.С. 2007. Фактор языковой идентичности в украинской политике.

- Космополис. № 2. С. 39-54.

Coker Ch. 2008. War, Memes and Memeplexes. - International Affairs. Vol. 84. No. 5. P. 903-914.

Dombrowski P., Reich S. 2018. Beyond the Tweets: President Trump's Continuity in Military Operations. - Strategic Studies Quarterly. Vol. 12. No. 2. P. 56-81.

Hafner-Burton E.M., Kahler M., Montgomery A.H. 2009. Network Analysis for International Relations. - International Organization. Vol. 63. No. 3. P. 559-592.

Sharma U., Kandwal S., Khatri S.K. 2018. A Link Prediction in Social Networks: A Fuzzy Cognitive Map Approach. - Ambient Communications and Computer Systems. Advances in Intelligent Systems and Computing. Vol. 696. Springer, Singapore. P. 463473.

Susser A. 2012. The 'Arab Spring': Competing Analytical Paradigms. - Bustan: The Middle East Book Review. Vol. 3. No. 2. P. 109-130.

Triana H.W., Wirman E.P., Kustati M., Refinaldi R. 2020. Social Practice on Facebook: Critical Discourse Analysis in the Process of Text Production. - Studies in English Language and Education. Vol. 7. No. 1. P. 1-21. 
Wellman B. 1983. Network Analysis: Some Basic Principles. - Sociological Theory. Vol. 1. P. 155-200.

\begin{abstract}
ABRAMOV Valery Leonidovich, Dr.Sci. (Econ.), Professor; Chief Researcher at the Center for Social and Political Studies, Institute for Integration Development Research, Russian Foreign Trade Academy (7 Vavilova St, Moscow, Russia, 117312); Chief Researcher at the Institute of International Economic Relations Research, Financial University under the Government of the Russian Federation (49 Leningradsky Ave, GSP-3, Moscow, Russia, 125993; valabr@yandex.ru) ZHIVALOV Vladimir Nikolaevich, Dr.Sci. (Econ.), Member of the Russian Academy of Natural Sciences; Analyst at the Center for Social and Political Studies, Institute for Integration Development Research, Russian Foreign Trade Academy (7 Vavilova St, Moscow, Russia, 117312; vzhivalov@vavt.ru); Professor of the Russian Presidential Academy of National Economy and Public Administration (bld. 1, 82 Vernadskogo Ave, Moscow, Russia, 119571)

IVANCHENKO Viktoria Sergeevna, Analyst at the Center for Social and Political Studies, Institute for Integration Development Research, Russian Foreign Trade Academy (7 Vavilova St, Moscow, Russia, 117312; viktoriia.ivanchenko@ gmail.com)

PEREHOD Elena Konstantinovna, Analyst at the Center for Social and Political Studies, Institute for Integration Development Research, Russian Foreign Trade Academy (7 Vavilova St, Moscow, Russia, 117312; eperekhod@vavt.ru) CHIMIRIS Ekaterina Sergeevna, Cand.Sci. (Pol.Sci.), $1^{\text {st }}$ category Analyst at the Center for Social and Political Studies, Institute for Integration Development Research, Russian Foreign Trade Academy (7 Vavilova St, Moscow, Russia, 117312; Chimiris@gmail.com); Associate Professor of the Department of Political Science, Faculty of Social Sciences and Mass Communications, Financial University under the Government of the Russian Federation (49 Leningradsky Ave, GSP-3, Moscow, Russia, 125993)

CHISTILIN Dmitry Konstantinovich, Cand.Sci. (Econ.), Academician of the Russian Academy of Natural Sciences; Head of the Center for Social and Political Studies, Institute for Integration Development Research, Russian Foreign Trade Academy(7Vavilova St, Moscow, Russia, 117312; chistilin@vavt.ru)
\end{abstract}

\title{
EXPERT APPROACHES TO THE INVESTIGATION OF SOCIAL NETWORKS ON THE INTERNET IN THE POST-SOVIET SPACE: MOLDOVA CASE
}

\begin{abstract}
The impact of social networks in the modern world is difficult to overestimate. They have become a full-fledged channel of political communication and influence on public opinion. In the case of using special analysis methods (cognitive maps, content analysis, conceptual models, intent analysis, etc.), the materials of social networks offer great opportunities for predicting the collective behavior of the population. In this article, the authors set themselves the task of reviewing current research and approaches to the analysis of social networks in the post-Soviet space. The authors' hypothesis is that pro-western countries often choose Facebook as the main platform for communication on the Internet, whereas Russianlanguage networks VKontakte and Odnoklassniki are considered as dangerous platforms promoting "Russian propaganda". The article makes a review of statistics on the use of different social networks in the countries of the near abroad. The results show, that the most popular are still the Russian-speaking networks, despite the intensive influence of western powers. At the same time, some Central Asian countries still have no the full access to Internet and that means the limited influence of social networks on population. The material of a specific study shows how partial distortion of data and conclusions regarding the use of social networks in the post-Soviet space occurs. Due to some peculiarities of Russian soft power strategy, its politics is usually categorized as propaganda. So, the results of social networks investigation may result in political statements, but not the scientific outcome.
\end{abstract}

Keywords: social networks, public opinion, propaganda, post-Soviet space, Russia 